Luciana Kuchenbecker Araújo

lubecker32@hotmail.com

1 estra em Letras e Linguística pela Faculdade de Letras da Universidade Federal de Goiás (UFG)

\section{O bom sujeito da ditadura militar em Coiás: um estudo sob a perspectiva de Michel Pêcheux sobre o Manifesto de Mauro Borges (1961)}

The good subject of military dictatorship in Coiás: a study under Michel Pêcheux's perspective about Mauro Borges' manifest (1961)

\section{Resumo}

Este artigo tem como objetivo promover uma reflexão acerca das posições-sujeito e da produção de sentidos materializadas no Manifesto à Nação, de 1961, redigido por Mauro Borges, governador de Coiás, no qual expõe seu posicionamento em defesa de seus ideais democráticos, constitucionais e contrários à tentativa de instauração do regime militar, após a renúncia do presidente Jânio Quadros. Para tanto, elegemos como referencial teórico os estudos de Michel Pêcheux, que defende a materialidade textual e o contexto discursivo como unidades de análise para a verificação das complexidades enunciativas, lançando mão da metodologia de análise sócio-histórica na interpretação das sequências discursivas recortadas do corpus. A partir das reflexões propostas, foi possível demonstrar de que maneira as diferentes posições-sujeito materializam-se discursivamente e como as sobreposições são processadas na relação entre o sujeito da enunciação e o sujeito universal, aos quais se afilia, como "bom sujeito", o governador Mauro Borges.

Palavras-chave: Sujeito; Sentidos; Discurso; Ditadura.

\section{Abstract}

This article conducts a discussion about the subject-positions and the production of meanings embodied in the Manifesto to the Nation (1961), written by Mauro Borges, former governor of Coiás, in which he exposes his position in defense of his democratic and constitutional ideals and against the attempt of the military regime establishment, after president]ânio Quadros' resignation. Therefore, we elected as theoretical model the studies of Michel Pêcheux, that defends the textual materiality and discursive context as units of analysis for the verification of the enunciative complexities, employing a methodology of social-historical analysis in the interpretation of the discursive sequences taken from the corpus. From the proposed reflections, it was possible to demonstrate how different subject-positions materialize themselves discursively and how the overlaps are processed in the relationship between the subject of enunciation and the universal subject, to which is affiliated, as "good man", the former governor Mauro Borges.

Keywords: Subject; Senses; Speech; Dictatorship. 


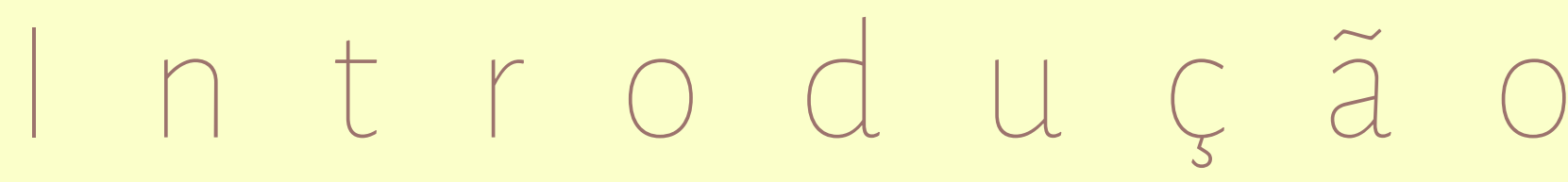

\section{Primeiras palavras}

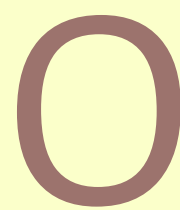

golpe militar de 1964 marcou o início de um dos capítulos mais polêmicos da história do Brasil, o qual perdurou de 1964 a 1985. Durante os 21 anos de ditadura, a nação assistiu cenas de desrespeito aos direitos constitucionais e humanos, perseguição política e censura. Os discursos que circularam por todo país antes da instauração do golpe foram decisivos para a formação de alianças políticas e divulgação dos posicionamentos das lideranças partidárias, como o Manifesto à Nação, redigido pelo governador do estado de Coiás, Mauro Borges, em 1961. Esses discursos fazem parte de um rico acervo para análise e reconhecimento das marcas identitárias e posicionamentos dos sujeitos e dos governos que marcaram os rumos da nossa história.

Assim, tomando como corpus o referido Manifesto à Nação (1961), este artigo buscou analisar as posições-sujeito materializadas nesse discurso, consideran- do que o dizer de Mauro Borges inscreve-se no lugar discursivo de governador de estado, o que possibilitou resgatar suas memórias e forças ideológicas de oficial das Forças Armadas, democrata, cidadão e cristão em defesa de seu posicionamento político pela legalidade jurídica constitucional.

Com base no referencial teórico da Análise do Discurso (AD) de orientação pecheuxtiana, selecionamos, para efeitos de análise, algumas sequências discursivas (doravante SD) relevantes ao funcionamento das distintas posições-sujeito presentes na materialidade do corpus. Este trabalho, por situar-se em um espaço/gênero discursivo breve, não tem pretensões de abarcar toda complexidade teórica da área, mas propor, sobretudo àqueles que iniciam suas pesquisas em $A D$, um exercício de reflexão acerca das materialidades linguísticas e discursivas inscritas na história da população goiana, considerando alguns conceitos basilares dos estudos de Michel Pêcheux 
(1997b), proponente desse campo de pesquisas sobre a linguagem.

Michel Pêcheux (1997b), que, a partir do materialismo histórico, do marxismo e da luta de classes propostos pela teoria de Althusser (2007), reconhece que os sujeitos e os sentidos são atravessados pelo inconsciente e pela ideologia. Segundo Pêcheux (1997b), as condições de produção e a memória discursiva são aspectos de extrema relevância para que se possa identificar as posições ideológicas dos sujeitos em qualquer procedimento de análise, já que esse autor interroga a Linguística a partir da historicidade dos enunciados e da produção dos sentidos regulada pelo tempo e pelo espaço das práticas humanas. Nessa perspectiva, Pêcheux (1997b, p. 130) reconhece o materialismo histórico como condição para analisar o sujeito e o discurso e, desse modo, somos convocados a realizar, nas primeiras partes desse estudo, uma breve contextualização histórica sobre os rumos da política brasileira entre o período de 1961 a 1964, precedente ao golpe militar, e sobre a história de Mauro Borges no cenário político de Coiás para que pos- samos compreender as condições de produção do Manifesto à Nação (1961), apresentado na terceira parte desse estudo. Na quarta parte, apresentamos a perspectiva teórica de Michel Pêcheux quanto aos procedimentos de análise de discursos para, finalmente, na quinta parte, procedermos à análise das SD recortadas do corpus e refletirmos sobre questões relativas à ideologia, às posições-sujeito e aos efeitos de sentidos produzidos no e pelo discurso.

\section{Contextualizações histórica e política de Goiás entre 1961 e 1964}

Para Teixeira (1994), o Manifesto à Nação (1961) pode ser considerado como um documento histórico que resguarda um período importante da história política de Coiás. Segundo consta registrado em ata da Câmara dos Deputados, o Manifesto foi transcrito e declarado como documento "que honra e orgulha o povo goiano e imortaliza o seu autor, para conhecimento da posteridade, numa prova eloquente 
de que os patriotas brasileiros de hoje souberam lutar pela grandeza da Pátria brasileira de amanhã" (TEIXEIRA, 1994, p. 54). Para que possamos observar o contexto de criação e circulação do referido documento, retomamos nosso passado através de uma breve narrativa histórica.

No dia 25 de agosto de 1961, o presidente da República Federativa do Brasil, Jânio Quadros (PR/PL), publicou uma Carta em que renunciava seu governo, conturbando o cenário político brasileiro. De acordo com a Constituição, o vice-presidente deveria assumir o poder, porém os ministros militares e políticos conservadores se opuseram à posse de João Goulart (PTB/PSD) que na ocasião estava na China, pois acreditavam que ele mantinha vínculos com o Partido Comunista Brasileiro (PCB) e com o Partido Socialista Brasileiro (PSB). E isso, segundo eles, representava uma ameaça ao país.

Como movimento contrário a esse ato inconstitucional, foi criada uma rede de resistência legalista contra o movimento golpista liderada pelo governador do Rio Grande do Sul, Leonel Brizola (PTB), e apoiada pelo então governador de Goiás, Mauro Borges. Usando a Rádio Brasil Central (RBC) para divulgar suas ideologias, o governo de Coiás passou a fazer parte do chamado Movimento da Legalidade, que tinha à frente a Rádio Cuaíba de Porto Alegre, Rio Grande do Sul (TEIXEIRA, 1994).

Em 28 de agosto de 1961, o governador de Coiás expôs sua discordância à inconstitucionalidade política dos ministros redigindo o Manifesto à Nação, pontuando argumentos contundentes a sua posição antigolpista. Como havia rumores de que a direita já armava o golpe ainda em 1961, Mauro Borges dirigiu-se ao povo com o objetivo de esclarecer sobre a real situação do país e mostrando à sociedade goiana e à nação brasileira o seu patriotismo. Teixeira (1994, p. 52-54) afirma que o Manifesto foi bastante divulgado na imprensa nacional (Imagem 1) e repercutiu de maneira positiva através de diversas manifestações de apoio ao governador feitas por deputados, vereadores, pelo PTB, pelo conselho da Maçonaria e representantes da União Nacional dos Estudantes (UNE). 
Mauro Denuncia os Ministros Militares e epnclamil o Povoù Resistencia Legalistą 0 w

OPOPULAR Brizola responde mensagem de Mauro: III Exército está conosco

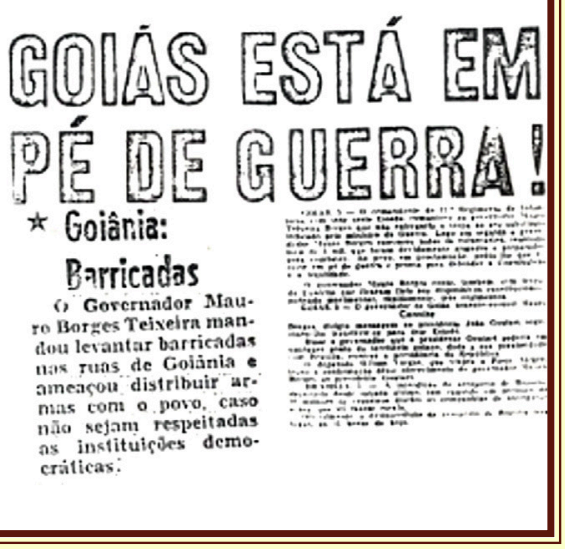

Imagem 1-Repercussão do Manifesto de Mauro Borges no jornal "O Popular"

Fonte: Teixeira (1994, p. 152)

Tanto o Manifesto (1961) quanto os demais Comunicados Oficiais, articulados pelo Chefe do Estado como estratégia de comunicação com seu eleitorado, são documentos que alcançaram repercussão nacional e os posicionamentos defendidos nesses discursos foram determinantes e marcaram a história da ditadura em Coiás, como podemos observar nos desdobramentos da crise em 1964.

Em 26 de novembro de 1964, uma multidão de goianienses a favor de Mauro Borges presenciou, na Praça Cívica, a

1 Edição de 20 de agosto de 1961. tensão provocada pela movimentação de tropas e tanques em torno da cidade (Imagem 2) e pelos rasantes de caças a jato da Força Aérea Brasileira (FAB). Essa ação deveu-se ao Decreto de Intervenção Federal em Coiás, que colocava o interventor Carlos de Meira Mattos à frente do poder do Estado no lugar de Mauro Borges, acusado de manter um governo com tendências comunistas, legitimando o golpe em Goiás e em todo território brasileiro.

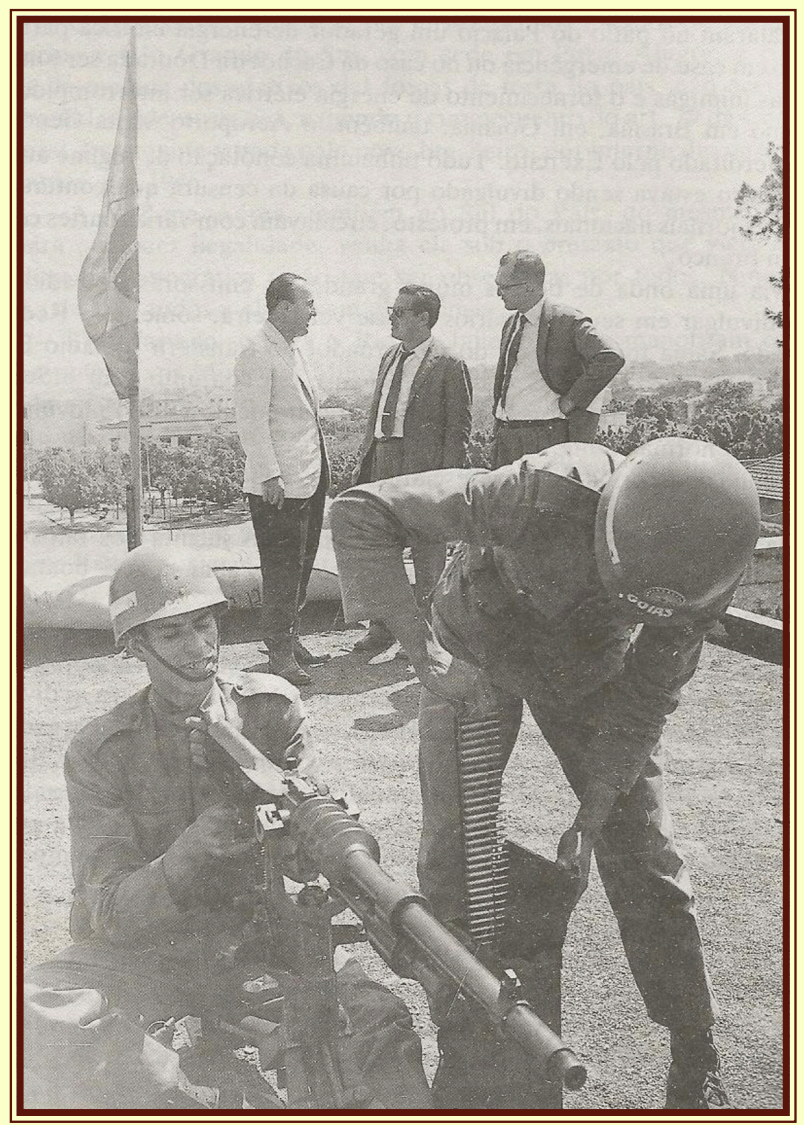

Imagem 2-Mauro Borges, aliados políticos e soldados se preparam para proteger Coiás da invasão militar.

Fonte: Teixeira (1994, p. 75). 


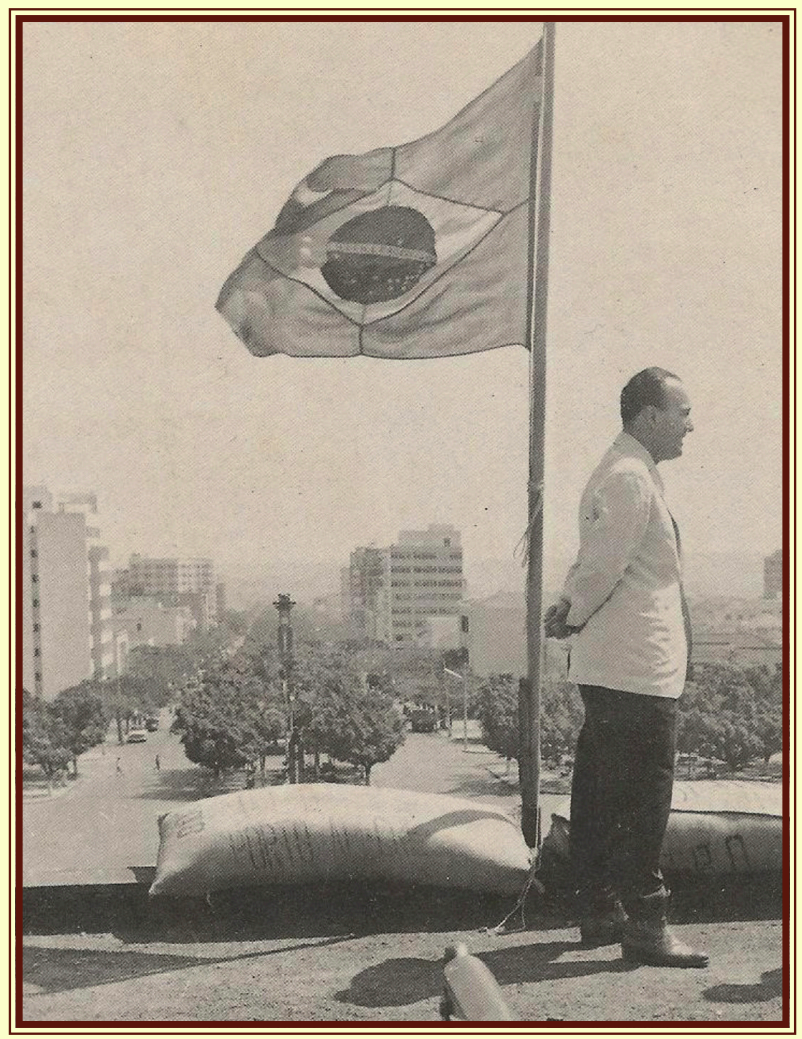

Imagem 3-Mauro Borges observa a capital de Coiás, Coiânia, do alto do palácio das Esmeraldas, na Praça Cívica.

Fonte: Teixeira (1994).

O sujeito empírico e sua história na política

Mauro Borges Teixeira nasceu em 15 de fevereiro de 1920, na cidade de Rio Verde, Goiás. Teve uma forte presença política na sua formação, pois era filho de Pedro Ludovico Teixeira, fundador de Goiânia, e presenciou toda movimentação e articulação que seu pai empreendeu durante o período da Revolução de 1930, da construção da capital do estado de Coiás e da resistência ao movimento paulista de
1932. Tornou-se militar ingressando na Escola Militar do Realengo, Rio de Janeiro, em 1938. Serviu junto à guarda presidencial de Cetúlio Vargas e, em 1948, conseguiu entrar para a Escola de Comando e Estado-Maior do Exército (Eceme) onde recebeu instruções teóricas e práticas de liderança para enfrentamento de crises, sob a ótica da organização militar.

Anos mais tarde, então Tenente-Coronel, participou do "golpe preventivo", deflagrado pelo Marechal Lott, em favor da posse do presidente eleito Juscelino Kubistchek. Nessa época, sua proximidade com a política aumentou e, apoiado pelo pai, candidatou-se e foi eleito deputado federal em 1958. Antes de encerrar esse mandato, conquistou, em 1961, o de governador de Coiás. À frente do poder do estado, viu seu governo ser ameaçado pelos rumores de intervenção militar após a renúncia de Jânio Quadros e, por meio de Manifestos e Comunicados Oficiais, dirigiu-se à Nação e ao povo goiano como medida de estabelecimento da ordem social e divulgação de seus ideais políticos. Foi, também, deputado federal (1959-1960; 1991-1994) e senador da República (1982-1990). 
É necessário ressalvarmos que a superficialidade das informações acerca dessa personalidade pública deve-se ao fato de considerarmos relevante que em qualquer exercício de análise é preciso que o analista reconheça e saiba discernir aquilo que é essencial para a realização de seu trabalho e se abstenha de posicionamentos pessoais, preconceitos, crenças, convicções ideológicas, políticas, religiosas. Por essa razão, expomos um pouco sobre a vida do governador, sujeito empírico, para que possamos observar, ao longo. da análise das SD recortadas do corpus, de que maneira suas identificações, escolhas, afiliações desenvolvidas ao longo de sua história aparecem materializadas em seu discurso.

\section{O discurso}

A considerável extensão do Manifesto nos motivou a apresentar apenas algumas SD recortadas do texto original. Devido à necessidade de cortes, as SD foram selecionadas no sentido de manter a materialidade linguística do autor com relação ao texto orignal ao mesmo tempo em que não ficasse demasiadamente prejudicada a produção de sentidos.

Manifesto à Nação

[SD1] Nesse momento histórico, em que se firmam as linhas mestras que determinarão o nosso futuro político, nos próximos anos, como representante do povo

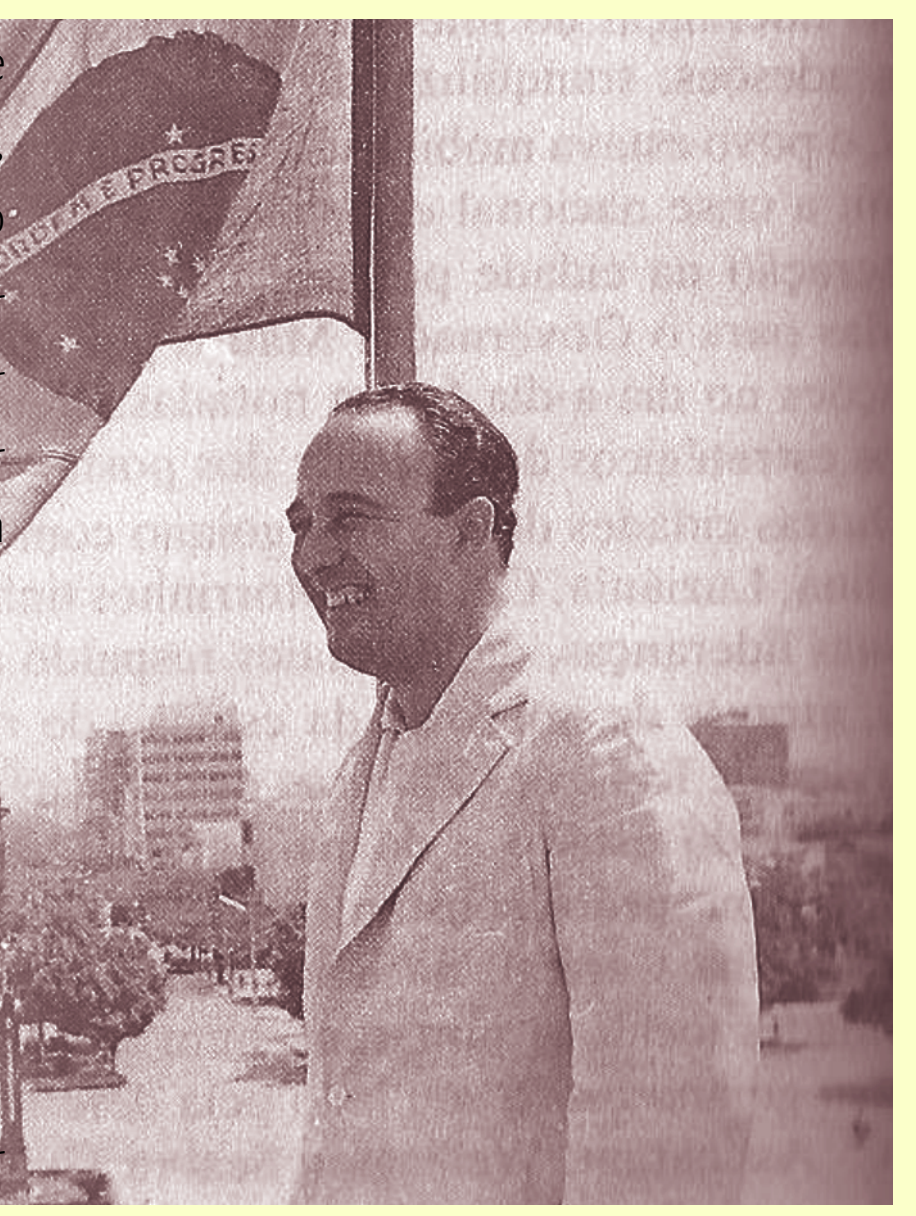


goiano, seria pusilaminidade ${ }^{2}$ furtar-me ao cumprimento do dever, deixando de fazer um pronunciamento claro, o que importaria cumplicidade com o que agora se trama contra o povo.

[SD2] Nessas condições, qualquer eleição que convocassem não passaria de uma farsa, pois não haveria liberdade no clima de tensão popular reinante e adredemente ${ }^{3}$ preparado. Duas conclusões ressaltam esses fatos: a) Caso o Congresso se submeta à pressão dos ministros militares, manipulados, ao que parece, pelo general Cordeiro de Farias, teremos apenas um governo fantoche, desvinculado das origens que o legitimaram - o consentimento dos governadores; b) Caso o Congresso não se submeta, será dissolvido e implantada uma ditadura militar, espú$\mathrm{ria}^{4}$ como todas as ditaduras, contando ou não com a presença de um elemento civil, para melhor ilaquear 5 a boa-fé popular. Em qualquer dessas hipóteses, haverá completo retorno do Brasil à situação de país caudatário ${ }^{6}$, republiqueta sem qualificação, sem rumo próprio na condução de seus destinos.

[SD3] A verdade é que apenas Jânio Quadros e João Goulart foram eleitos pela

2 Covardia.

3 Previamente.

4 Falsa.

5 Enlaçar, prender.

6 Subserviente, que não tem opinião e atitude próprias. vontade livre e soberana do povo brasileiro e somente eles poderão governar o Brasil até que se esgotem os seus mandatos e o poder seja entregue aos sucessores legitimamente escolhidos. [Só] há um caminho digno, democrático e constitucional, na letra e no espírito da lei: a posse do vice-presidente João Coulart, no cargo vago da Presidência da República.

[SD4] Fora disso, será aceitar uma ditadura militar retrógrada, sem programas e sem rumo, a não ser a obstinação de que o Brasil é imaturo para pensar com a própria cabeça e andar com os próprios pés. [...] Não sou nem jamais fui comunista. Coerentemente, em toda a minha vida, sempre defendi essas idéias.

[SD5] Quando acatamos e defendemos o direito impostergável de o Brasil manter relações diplomáticas e comerciais com todos os povos do mundo, não estamos dando preferência à esquerda ou à direita, não estamos ensaiando a renúncia de nossas profundas convicções democráticas e cristãs, pois temos a certeza de que o Brasil pode resolver todos os seus problemas sem a perda das liberdades fundamentais, mantendo as linhas mestras do regime vigente sem a perda de nossas caras tradições de povo católico, em sua maioria.

[SD6] Na qualidade de modesto membro do glorioso Exército de Caxias, Osório, 
Floriano e tantos outros heróis do Brasil, tendo tido toda a formação da juventude e da vida madura nas escolas militares e nas fileiras do Exército, conheço a sua profunda vocação democrática e sua vinculação ao povo e sei que ele não trairia os interesses da Pátria, sei que ele não funcionaria como um guarda pretoriano de interesse espúrio, a esmagar, com a força de suas armas que o povo lhe pôs nas mãos para defendê-lo, a vida dos patriotas.

[SD7] Se os ministros militares ultrapassarem as raias da legalidade em que legitimam suas determinações, estão os subordinados exonerados de dever de obediência, pois a ordem legal difere da inconsciência.

[SD8] Se a vontade do povo não for respeitada, se tentarem mistificá-la e em seu nome ousarem lançar o país na degradação de uma ditadura, sob a alegação [...] de que era preciso salvá-lo da ameaça comunista, só nos resta um caminho fazer o apelo dos grandes momentos e das grandes crises: a resistência legalista, democrática e patriótica.

[SD9] Convocamos a resistência, a repulsa aos aventureiros, a todos os governadores, prefeitos e vereadores que hauriram7, no consentimento popular, a

7 Tirar para fora de lugar profundo, esgotar. legitimidade do seu mandato e cuja política passaria agora a depender, unicamente, do beneplácito de usurpadores.

[SD10] Aos companheiros e ao povo de Goiás, peço para que se mantenham calmos, que aguardemos as decisões do Congresso e dos responsáveis pela manutenção da paz social, pois das atitudes deles dependerá a nossa palavra de ordem.

Mauro Borges Teixeira, Governador do Estado de Goiás

Goiânia, 28 de agosto de 1961 (TEIXEIRA, 1994, p. 49-52).

\section{Procedimentos de análise de discurso em Pêcheux}

Para Pêcheux (1997b), a Análise do Discurso (AD) não deve ser reduzida a uma prática hermenêutica de interpretação dos discursos, mas entendida como dispositivo que permite analisar a textualização do político para que seja possível compreender não somente a maquinaria linguística e os textos políticos, mas, sobretudo, a relação empírica entre o simbólico e o poder na cadeia discursiva. Dessa forma, para que possamos debru- 
çar-nos sobre a materialidade discursiva do corpus, é necessário recorrermos a alguns conceitos basilares da obra de Michel Pêcheux (1997b), que, a partir do materialismo histórico, do marxismo e da luta de classes propostos pela teoria de Althusser (2007), reconhece que os sujeitos e os sentidos são atravessados pelo inconsciente e pela ideologia.

\section{Pêcheux (1997b, p.}

131) propõe uma teoria materialista do discurso, uma teoria não subjetiva da sub-

Os sujeitos são produzidos nos e pelos discursos e a linguagem deve ser apreendida como sistema capaz de apresentar certa ambiguidade, o elemento material da análise

\section{linguística}

jetividade ao referir-se

a um mundo de bases econômicas, de definição de lugares sociais a partir do poder aquisitivo, da pertença de classes sociais distintas. Isso significa empreender que a subjetividade, como lugar em que são construídas as 'verdades' por meio da exterioridade discursiva, é o que torna possível o funcionamento das ideologias, e, por essa razão, o autor limita a autonomia do objeto linguístico através da descentralização da subjetividade.
Dessa forma, em Pêcheux (1997b) encontramos a teorização de um objeto cujos procedimentos de análise relacionam as condições de produção aos processos de produção dos discursos, que são sempre determinados por uma relação histórica. O caráter político do trabalho desse autor refere-se ao materialismo concreto ao pensar a existência social e real dos sujeitos que falam, funcionam, interagem, trabalham, têm suas verdades, suas identidades, que assumem uma forma sujeito do discurso e que são assujeitados por uma ideologia dominante.

Podemos compreender, dessa maneira, que os sujeitos são produzidos nos e pelos discursos e que a linguagem deve ser apreendida como sistema capaz de apresentar certa ambiguidade, o elemento material da análise linguística. A materialidade textual e o contexto discursivo são, portanto, unidades de análise essenciais para a verificação das complexidades enunciativas: 
Um discurso é sempre pronunciado a partir de condições de produção dadas: por exemplo, o deputado pertence a um partido da oposição: é porta-voz de tal ou tal grupo que representa tal ou tal interesse, ou então está "isolado" etc. Ele está, pois, bem ou mal, situado no interior da relação de forças existentes entre os elementos antagonistas de um campo político dado: o que diz, o que anuncia, promete ou denuncia não tem o mesmo estatuto conforme o lugar que ele ocupa; a mesma declaração pode ser uma arma temível ou comédia ridícula, segundo a posição do orador e do que ele representa, em relação ao que diz (PÊCHEUX, 1997b, p. 77).

Assim, somos convocados a pensar a opacidade do texto objetivando compreender aquilo que o sujeito diz em relação a outros dizeres possíveis e ao que ele não diz, bem como a refletir sobre a seguinte questão: por que esse enunciado (o dito) e não outro em seu lugar? Para Pêcheux (1997b), o interdiscurso ou a memória discursiva (o já dito) é o que torna possível todo dizer, pois todo dizer carrega consigo um significado precedente adquirido em outro lugar e independentemente.

Em se tratando de um corpus consti- tuído por um discurso político, a discussão não é tão simples, é preciso que o analista conheça ou pelo menos tenha uma ideia do que seja a democracia e a ditadura no Brasil. Como os dois termos configuram uma relação dicotômica, é necessário também que se tenha bastante zelo ao abordar esses conceitos, pois não se trata de um debate tranquilo, homogêneo e consensual como se a democracia representasse o lado positivo e bom da história e a ditadura o lado negativo, obscuro. Nesse caso, é preciso que se observe o fato de que muitas pessoas desejaram a ditadura ou uma certa disciplinarização administrativa do país, outras condenaram a arbitrariedade e a inconstitucionalidade jurídica ditatorial ao considerarem contraditório o estabelecimento da ordem e da segurança sociais por meio da violência, opressão e punições de natureza diversa como solução para os problemas políticos. A tarefa do analista, então, é penetrar, desvendar a materialidade discursiva (os ditos e os não ditos) considerando a linguagem não apenas como representação do objeto, transparente e reveladora de verdades, mas reconhecendo seu mascaramento, sua opacidade, 
sua exterioridade, para que possa, então, pensar a produção de sentidos.

Olhar teórico para o corpus: as formas-sujeito e a produção de sentidos na perspectiva de Michel Pêcheux [é] a ideologia que fornece evidências pelas quais "todo mundo sabe o que é um soldado, um operário, um patrão, uma fábrica, uma greve, etc., evidências que fazem com que uma palavra ou um enunciado 'queiram dizer o que relamente dizem"' e que mascaram assim, sob a 'transparência da linguagem', aquilo que chamaremos o caráter material das palavras e dos enunciados.

A partir dessa reflexão, podemos comPêcheux (1997b) reconhece que a linguagem é materializada na ideologia ao discutir de que maneira uma se manifesta na outra, avaliando a especificidade de sua exterioridade e associando os efeitos de sentidos à materialidade linguística produzida nas relações entre os sujeitos, os espaços de enunciação e as condições de produção. Por isso, ao concebermos o discurso como sendo efeito de sentidos entre locutores, um objeto social e histórico em que o linguístico está pressuposto, é preciso explicar os mecanismos de determinação histórica dos processos de significação através da análise do funcionamento discursivo e do conceito de Formação Discursiva (FD). A esse respeito, Pêcheux (1997b, p. 146) afirma que preender que a ideologia, como forma de dominação, penetra a existência dos sujeitos nos processos de subjetivação, de tudo aquilo que é produzido pela exterioridade através de práticas concretas materializadas discursivamente. Essa visão do estudioso deve-se ao fato de que toda exterioridade habita a subjetividade, todos os elementos exteriores produzem e constituem os sujeitos, pois não é possível pensarmos em um "não-sujeito", um indivíduo puro, livre, práticas socias, às experiências humanas, e isso faz com que seja inevitável as (des)identificações com as mais distintas e variadas formações ideológicas (FI). Nesse sentido,

os indivíduos "são interpelados em sujeitos falantes [...] por formações discursivas imune, ileso aos estímulos externos, às 
que representam na linguagem as formações ideológicas que the são correspondentes", o que significa que o sujeito se identifica com a formação discursiva que o domina (PÊCHEUX, 1997b, p. 198).

Para ilustrarmos esse pensamento, podemos considerar que na negação (ou seria afirmação?) "Não sou nem jamais fui comunista" (SD4) já estão postos alguns dogmas, a (des)crença do sujeito a outro(s) sistema(s) econômico(s), seu posicionamento político através da identificação com aquilo que o representa, a democracia, por exemplo. Essa criação de um lugar de identidade no discurso é o que Pêcheux (1997b, p. 159) chama de forma-sujeito. Para o autor, a luta de classes representa a construção ideológica dos sujeitos que não se realizam no campo das ideias, mas nas práticas discursivas, assim como os discursos produzidos por Mauro Borges em defesa de seu posicionamento político-ideológico, da integridade física do povo e do estado, representados na posição de governador.

Contrapondo-se à filosofia do idealismo linguístico, que converge à existência espontânea do sujeito como fonte, origem ou causa em si, e à transparência dos sentidos, Pêcheux (1997b, p.
155) concebe os sujeitos, como já mencionamos, não como dados a priori, mas constituídos no discurso. Assim, a noção de sujeito para o estudioso é determinada pela posição, pelo lugar de enunciação no interior de uma FD regulada por uma $\mathrm{FI}$, já que essas formações definem o que pode e deve ser dito a partir de uma dada posição na conjuntura histórica. Dessa maneira, podemos compreender que a interpelação do sujeito pela ideologia, conceito que Pêcheux pega emprestado de Althusser (1974, p. 104), faz com que ele assuma uma forma no discurso e tenha a ilusão de ser a fonte, a origem de seu dizer. Para o autor, essa ilusão de liberdade de escolha, de associação, de identificação a determinadas FD é condição para a existência do sujeito (PÊCHEUX, 1997b, p. 170). Trata-se, pois, de uma contradição para a existência e condição do sujeito na AD ao promover todo apagamento do lugar de funcionamento da ideologia que interpela o indivíduo enquanto sujeito.

Mauro Borges, ao afirmar sua liberdade de escolha "Não sou nem jamais fui comunista" (SD4) apresenta valores e uma posição identitária; e essa convicção, esse lugar de verdade, faz com que ele assuma, enquanto sujeito discur- 
sivo, uma forma no discurso. Temos, assim, o que Pêcheux (1997b) concebe como sujeito da enunciação, assujeitado, que toma uma posição consciente no ato comunicativo (não ser comunista) e o sujeito universal, o representante máximo da FD que regula o que pode e o que deve ser dito no seu interior, pois todo mundo tem uma ideia do que seja um Chefe de Estado; já esperamos que o seu dizer corresponda à FD a qual se inscreve no lugar de governador.

O discurso se materializa como dúvida, soa como protesto, produzindo revolta e questionamento, já que não há uma coincidência entre o lugar de enunciação, do enunciador e do discurso
Pêcheux (1997b) afirma não ser possível a sobreposição plena dessas duas formas sujeito ao considerar uma maior ou menor incidência entre ambas no ato enunciativo. Essas variações de identificação correspondem ao que o autor chama de modalidades de posição-sujeito. A primeira modalidade, que é adjetivada como "bom sujeito", pressupõe maiores identificações e a coicidência entre os sujeitos da enunciação e universal, é o que podemos observar no Manifesto à Nação, de 1961 . cujos dizeres da enunciação correspondem à posição ideológica do lugar de governador, de sujeito universal. A segunda é denominada "mau sujeito", pois revela um movimento de desidentificação do sujeito com sua FD ao fazer/dizer algo diferente daquilo que se espera dele ao se colocar contra seu lugar de enunciação. Não há uma convergência entre ambos, há uma separação. Dessa maneira, o discurso se materializa como dúvida, soa como protesto, produzindo revolta e questionamento, já que não há uma coincidência entre o lugar de enunciação, do enunciador e do discurso. Poderíamos observar claramente o que diz Pêcheux e Mauro Borges, no lugar de um Manifesto, no qual se posiciona em defesa de seu estado e seu povo, elegesse como gênero discursivo um Poema em que enaltecesse a grandeza das forças armadas do Brasil.

A terceira modaliade surge a partir da observação de Pêcheux sobre o "caráter historicamente novo da prática ideológica do proletariado" (PÊCHEUX, 1997b, p. 201), uma tentativa de ex- 
plicar as falhas de querer determinar tudo pela ideologia que, enquanto categoria, não desaparece, funciona às avessas através do desarranjo dos processos de Fl. Trata-se de uma modalidade de desidentificação entre o sujeito da enunciação e o sujeito universal, ou seja, um deslocamento da forma sujeito mas não sua anulação. Pêcheux (1997b, p. 201-202) adverte, entretanto, que

a ideologia "eterna" enquanto catergoria, isto é, enquanto processo de interpelação dos indivíduos em sujeitos, não desaparece, ao contrário, funciona de certo modo às avessas, isto é, sobre e contra si mesma, através do 'desarranjo-rearranjo' do complexo das formações ideológicas (e das formações discursivas que se encontram intrincadas nesse complexo).

A exemplo do que diz o autor sobre a forma de desarranjo-rearranjo que configura a (des)identificação do sujeito com a Fl, portanto com as FD, mencionaremos o fato que sucedeu, três anos após a publicação do $M a-$ nifesto à Nação, a respeito do (re)posicionamento político-ideológico de Mauro Borges. Desapontado com a administração João Coulart, o governador queixava-se de contenção de recursos federais destinados a Goiás e passou a apoiar o golpe com a indicação do Marechal Castello Branco à Presidência da República.

Isso implica considerarmos que há uma identificação temporária do sujeito em relação à $\mathrm{Fl}$ que o representa, pois, nesse caso, houve uma (des) identificação do sujeito em relação à ideologia democrática, contradizendo sobremaneira seu discurso anterior "Não sou nem jamais fui comunista" (SD4) ao identificar-se com a ideologia comunista, mesmo não sendo de forma espontânea. Assim, o enunciado é atrelado, de modo automático, às determinações das formações ideológicas nas formações discursivas. Para Pêcheux (2010, p. 102), qualquer "formação social implica a existência de posições políticas e ideológicas que não são obra de indivíduos, mas se organizam em formações, estabelecendo entre si relações de antagonismo, de aliança ou de domínio".

Conforme pudemos observar, a concepção de sujeito proposta por Pêcheux (1997b) é marcada por uma forte relação de posições entre os sujeitos e de natureza sócio-histórica sendo, assim 
como os sentidos, constituídas num processo simultâneo através da interpelação ideológica. O autor afirma que

as palavras, expressões, proposições, etc., mudam de sentido segundo as posições sustentadas por aqueles que as empregam, o que quer dizer que elas adquirem seu sentido em referência a essas posições, isto é, em referência às formações ideológicas nas quais essas posições se inscrevem no processo sócio-histórico em que palavras, expressões, proposições são produzidas (PÊCHEUX, 1997b, p. 146-747).

Para prosseguirmos com a análise das SD, é necessário que pensemos, inicialmente, na estrutura composicional do enunciado de Mauro Borges. Isso significa que devemos olhar para o gênero discursivo manifesto, no qual se insere o discurso de Mauro Borges, e questionarmos os motivos da escoIha desta e não de outras formas de enunciação. Manifestos nos textos, os gêneros organizam nosso discurso e são definidos por Bakhtin (2003) como tipos relativamente estáveis de enunciados. Sem a presença dos gêneros, a comunicação verbal seria praticamente impossível, pois eles surgem através de condições específicas de produção e, à medida que crescem em complexidade, ampliam o repertório de gêneros discursivos.

Pêcheux (1997b) trata os gêneros discursivos como unidade das FD que determinam o que pode e deve ser dito em determinadas condições de produção, porém, muitas situações também determinam o gênero discursivo a ser utilizado pelo sujeito. O gênero manifesto é geralmente utilizado para declarar publicamente as razões que justifiquem algumas ações ou para que sejam reivindicados certos direitos, visando ao convencimento de outros por meio de marcas de persuasão, apelo emocional e, muitas vezes, acentuando uma polêmica já existente. Nas palavras de Pêcheux (1997b, p. 147), as FD "são aquilo que, numa formação ideológica dada, determina o que pode e deve ser dito (articulado sob a forma de uma arenga, de um sermão, de um panfleto, de uma exposição, de um programa, etc)", ou seja, aquilo que o sujeito pode e deve dizer em determinada situação está ligado às condições de produção. Entretanto, esses dizeres, conforme observamos na fala de Pêcheux, são determinados pelas FD, articulados e organizados na for- 
ma de gêneros discursivos, que participam da situação de produção dos discursos. Dessa forma, percebemos que no discurso de 28 de agosto de 1961, a situação determinou o gênero, pois, ao eleger esse gênero discursivo, o governador não pretendia apenas comunicar um fato ocorrido ou que por ventura viesse a ocorrer, mas argumentar com o objetivo de convencer a população a respeito de seu posicionamento político, direcionando para si o olhar dos interlocutores ao assumir seu lugar no ato comunicativo, respondendo por ele enquanto sujeito enunciador e cumprindo com seu dever de chefe de estado, e, enquanto sujeito universal, de representar, defender, informar e tranquilizar seus eleitores.

Os fatos que sucederam à publicação do Manifesto à Nação, com a invasão das forças armadas em Coiânia, permitem-nos reconhecer que o gênero discursivo, nesse caso, determinou a situação, já que os efeitos de sentidos provocados pelo discurso do governador soaram como afronta, desafio e auferismo de poder aos militares. Isso significa compreender que todo enunciado é linguisticamente descritível como uma série de pontos de derivas possíveis oferecendo lugar à interpretação. Nas palavras de Pêcheux (1997a, p. 53), "toda descrição está exposta ao equívoco da língua: todo enunciado é intrinsecamente suscetível de tornar-se outro, diferente de si mesmo, se deslocar discursivamente de seu sentido para derivar para um outro".

Consideramos relevante apontarmos também o fato de que todo o governo de Mauro Borges foi marcado pela circulação de vários discursos inscritos nos mais diversos suportes e gêneros discursivos, a exemplo, os manifestos, os comunicados, os panfletos que eram distribuídos pelo centro da capital, além daqueles que eram veiculados na Rádio RBC. Essas estratégias de comunicação eleitas pelo governador, para dirigir-se a seu povo, nos revela indícios de uma forma de gestão de 
Governo voltada ao diálogo, promovendo a aproximação entre o povo e seu representante.

$\mathrm{Na}$ (SD1) podemos perceber que Mauro Borges marca seu lugar no discurso de governador como sujeito universal, representante do povo goiano. Esse lugar de enunciação pressupõe os saberes que o autoriza a tomar esse lugar no discurso, pois, conforme Foucault (2001), existe, na ordem do discurso, três tipos de interdição, uma delas trata-se do direito privilegiado ou exclusivo do sujeito que fala, já que qualquer um não pode falar de qualquer coisa e estabelecer a relação entre os saberes e os poderes que (des)autorizam os nossos dizeres. No caso específico do sujeito Mauro Borges, há de se tentar caracterizar o sujeito universal que reflete a FD da democracia a qual se filia, consciente e livremente, enquanto sujeito que enuncia de um lugar social e historicamente marcado. O que se espera da fala de um governador de Estado democrático e o que todos sabem, "o que pode ser dito", desde uma dada posição na conjuntura (PÊCHEUX, 1997b, p. 160), constituem o sujeito universal da FD.
A filiação de Mauro Borges à FD democrática fica explícita na SD2 quando ele afirma não ser possível estabelecer, sem que haja liberdade, o exercício maior da democracia, a eleição pelo voto popular, que foi posta em xeque ao suscitar o eminente clima de tensão. Nesse caso, o governador relaciona os termos liberdade e democracia em oposição à falsidade e ditadura, termos que não fazem parte dos saberes que podem ser discursivizados em uma FD da democracia, que é onde se inscreve esse discurso e cuja posição sujeito dominante é a de governador. Na SD4 encontramos um repertório de adjetivações pejorativas em relação à situação do país caso confirmassem os rumores do golpe: governo fantoche, ilaqueação da boa-fé popular, país caudatário, republiqueta sem qualificação, sem rumo próprio na condução de seu destino. Esse tipo de estratégia discursiva, ao atribuir juízo de valor negativo à ideologia ditatorial, permite que o governador revele a seus interlocutores que a ordem democrática seria o antônimo, o oposto dos termos selecionados para que se estabelecesse uma crítica incisiva antigolpista. Entretanto, se por um lado o governador associa adjetivações nega- 
tivas à ditadura, por outro, conforme percebemos na SD3, relaciona termos como verdade, liberdade, soberania e dignidade à constitucionalidade democrática. Isso se confirma, por um lado, na condição de um nacionalista ao defender a democracia, a lei e a ordem constitucionais; por outro, dentro de um contexto marcado por conflitos de interesses em torno da distribuição e redistribuição de poder, Mauro Borges buscou assegurar uma proeminência política para fortalecer e manter politicamente seu governo e, consequentemente, seu poder.

Podemos observar que as adjetivações pejorativas ao regime militar reincidem no discurso do governador e vão se tornando cada vez mais recorrentes, conforme percebemos na SD4, ao afirmar que aceitar a ditadura significa retrocesso, imaturidade e incapacidade de autonomia, fazendo com que os interlocutores associem a democracia aos termos opostos àqueles que simbolizam esse período ditatorial. O que observamos funcionando nessa SD4 é o atravessamento ideológico das memórias (saberes) do regime não democrático, funcionando como discurso transverso, possível graças à "ascendência dos processos ideológico-discursivos so- bre o sistema da língua e ao limite da autonomia, historicamente variável, desse sistema (PÊCHEUX, 1997b, p. 165). Ao analisarmos o enunciado "Não sou nem jamais fui comunista" (SD4), observamos que o governador seleciona seis palavras para construir o período, sendo que três delas carregam consigo caráter de negação (Não, nem, jamais) para enfatizar sua posição contrária ao comunismo. Mesmo que seu posicionamento democrático não esteja explícito nesse período, ao tomarmos conhecimento das condições de produção do discurso, do contexto de enunciação, é possível reconhecer sua identificação com um sistema econômico em detrimento de outro, e é essa a materialidade, segundo a perspectiva de Pêcheux, para a qual o analista deve direcionar seu trabalho.

Podemos constatar na SD5 que Mauro Borges defende os interesses e instituições nacionais em face dos estrangeiros, no seu entendimento, através da legalidade democrática e do nacionalismo enquanto processos complementares entre si. A voz plural (acatamos, defendemos, estamos) indica a identificação do discurso do sujeito com a coletividade que, no decorrer das SD5 e SD6, fica claro, e é possível infe- 
rirmos que Mauro Borges ocupa outras posições sujeito além de Chefe de Estado. Seus dizeres nessas SD revelam deslocamentos significativos da posição do sujeito enunciador como cidadão, católico e ex-militar. Mesmo ocupando diferentes posições, o sujeito Mauro Borges, assujeitado aos saberes que circunscrevem a forma sujeito universal dessa FD, inscreve-se num mesmo lugar discursivo ressignificando-o: o lugar de governador.

As interpretações de Mauro Borges traduzem uma visão de mundo de inspiração cristã, na qual impera um ideal de sociedade baseada na cooperação, sem lutas de classes, com predomínio do interesse coletivo em detrimento dos individuais, visando à ordem social traduzida na Constituição. Essa estratégia de associar o idealismo político ao religioso é recorrente nas FD de natureza política. Trata-se, portanto, de uma tentativa de mobilizar a opinião pública através dos dogmas e crenças religiosas, como se o "certo" fosse ser democrata e cristão. Todavia, essa relação empírica entre o simbólico e o poder na cadeia discursiva torna-se um equívoco enquanto estratégia de persuasão na medida em que não se trata de um status permanente, já que, de acordo com a teoria de Pêcheux (1997b), pode ocorrer a desidentificação dos sujeitos com as FI fazendo com que estes se identifiquem com outras. Prova disso é o fato de não ser possível acreditarmos com veemência que hoje, de fato, somos católicos em maioria, haja vista a representatividade exponencial do número de templos evangélicos, por exemplo, espalhados pelos quatro cantos do país.

O deslocamento da posição-sujeito expresso na fala de Mauro Borges na SD6 oscila entre governador e ex-militar. No entanto, numa relação tensa entre o distanciamento e a identificação, a posição-sujeito dominante é a de governador que se envolve com as causas democráticas e foi eleito pelo voto popular. Sob esse lugar discursivo, o mesmo sujeito enunciador ocupa distintas posições-sujeito sem romper com os saberes/sentidos da FD em que o seu discurso se inscreve: de governador, ex-militar, cidadão, cristão. Nota-se que a formação militar de Mauro Borges proporcionou-lhe um perfil de administrador, assegurando os princípios de racionalidade e capacidade de planejamento e execução em situação de conflito. O posicionamento de Mauro Borges retrata a maneira como ele buscou articular a prática militar com a ação política refletindo em suas práticas institucio- 
nais sua visão de mundo. Por meio das estratégias propostas por ele, é possível depreender sua coerência ao posicionar-se politicamente naquele contexto com base em sua formação militar, cristã e democrática. O que observamos nesse conjunto de SD analisadas é o embate constante entre os saberes/sentidos que se inscrevem em duas FD contraditórias entre si: a FD da democracia e a FD da ditadura. Assim, os dizeres permitidos na FD da ditadura são rechaçados pela posição de chefe de estado que se inscreve na FD democrática. Na SD8, podemos empreender que sua memória discursiva, de outras FD, como as que presenciou na infância através das lutas políticas do pai, Pedro Ludovico Teixeira, fundador de Coiânia, ilustram a teoria de Pêcheux (2010) ao considerar que os indivíduos "são interpelados em sujeitos falantes [...] por formações discursivas que representam na linguagem as formações ideológicas que lhe são correspondentes" (PÊCHEUX, 1997b, p. 198), o que significa que o sujeito se identifica com a FD que o domina.

\section{Ao convocar a resistência e a repulsa aos} aventureiros, propostas na SD9, temos a impressão de que essa atitude significa uma relativa independência e desobediência do governador de Coiás. Nesse sentido, há um tom de reprovação aos políticos profissionais, tidos como movidos apenas por interesses menores, que se contrapõem aos ideais nacionalistas do governador de Coiás, expressos em um projeto de sociedade menos desigual e democrática e um pedido de manutenção da tranquilidade por parte da população em relação aos desdobramentos da crise, conforme podemos verificar na SD10.

\section{Considerações finais}

O exercício de análise que apresentamos demonstra de que maneira as diferentes posições-sujeito e Fl aparecem no discurso com sobreposições processadas na relação entre o sujeito da enunciação e o sujeito universal aos quais se afilia, no referido discurso publicado em 1961, como "bom sujeito", o governador Mauro Borges. Buscamos, através da materialidade linguística do corpus, refletir sobre a pluralidade de posições-sujeito, demonstrando que não são fixas, mas construídas e atravessadas, e podem aparecer no discurso como estratégia para persuadir seus interlocutores, o povo brasileiro, 
a população goiana, a corporação militar.

A partir das reflexões apresentadas neste trabalho, foi possível demonstrar de que maneira as diferentes posições-sujeito e Fl aparecem no discurso e como as sobreposições processadas na relação entre o sujeito da enunciação e o sujeito universal. Pudemos verificar que a noção de sujeito universal, embora acionada pelo dispositivo analítico, mostrou não dar conta da complexidade das ocorrências do evento discursivo. Por isso buscamos, através da materialidade linguística do corpus, refletir sobre a pluralidade de posições-sujeito, demonstrando que elas não são fixas, mas construídas e atravessadas no e pelo discurso.

\section{Referências}

ALTHUSSER, L. Ideologia e aparelhos ideológicos do Estado. Lisboa: Presença-Martins Fontes, 1974.

Aparelhos ideológicos de Estado. Tradução de Walter]. Evangelista e Maria Laura V. de Castro. São Paulo: Craal, 2007.

BAKHTIN, M. Estética da criação verbal. Tradução de Paulo Bezerra. São Paulo: Martins Fontes, 2003.

FAVARO, Tereza Cristina Pires. Movimento da legalidade (1961): resgatando o protagonismo de Mauro Borges. Anos 90, Porto Alegre, v. 18, n. 33, p. 41-65, jul. 2011. Disponível em: <http://seer. ufrgs.br/anos90/article/viewFile/25398/18240>. Acesso em: 10 set. 2014.

FOUCAULT, M. Aordem do discurso. São Paulo: Loyola, 2001.

PÊCHEUX, M. Odiscurso: estrutura ou acontecimento. Tradução Eni Pulcinelli Orlandi. Campinas: Pontes, 1997a [1983].

Semântica e discurso. Tradução de Eni P. Orlandi et al. Campinas: Editora da Unicamp, 1997b.

Análise automática do discurso. Campinas: Editora da Unicamp, 2010.

TEIXEIRA, Dulce Loyola. Mauro Borges e a crise político-militar de 1967 em Coiás: movimento da legalidade. Brasília: Senado Federal, Centro gráfico, 1994.

TEIXEIRA, Mauro Borges. Temposidose vividos: minhas experiências. Coiânia: [s.n.], 2002. 